\title{
Clinical Characteristics and Mortality Profile of COVID-19 Patients Aged less than 20 years Old in Pernambuco - Brazil
}

\author{
Gabrielle R. Sena, ${ }^{1,2,3 *}$ Tiago P. F. Lima, ${ }^{1,4}$ Suely A. Vidal, ${ }^{1}$ Maria do Carmo M. B. Duarte, ${ }^{1}$ Patrícia G. M. Bezerra, ${ }^{1,2}$ \\ Eduardo J. Fonseca Lima, ${ }^{1,2}$ Cynthia Braga, ${ }^{1,5}$ Lívia B. de Andrade, ${ }^{1,2}$ Mecneide M. Lins, ${ }^{1}$ Leuridan C. Torres, ${ }^{1}$ \\ Jurema T. O. Lima, ${ }^{1,2}$ and Maria Julia G. Mello ${ }^{1}$ \\ ${ }^{1}$ Instituto de Medicina Integral Prof. Fernando Figueira, Recife, Brazil; ${ }^{2}$ Faculdade Pernambucana de Saúde, Recife, Brazil; ${ }^{3}$ Universidade de \\ Pernambuco, Recife, Brazil; ${ }^{4}$ Instituto Federal de Pernambuco, Garanhuns, Brazil; ${ }^{5}$ Instituto Ageu Magalhães - Fiocruz PE, Recife, Brazil
}

\begin{abstract}
COVID-19 in children and adolescents has low frequency, severity, and fatality rate all over the world. A cross-sectional study was conducted to assess the epidemiological and clinical aspects of COVID-19 in patients younger than 20 years in Pernambuco (Brazil), with cases confirmed by reverse-transcriptase-PCR SARS-CoV-2 between 13 February and June 19, 2020, reported on information systems. Data regarding age (<30 days, 1-11 months, 1-4 years, 5-9 years, 10-14 years, and 15-19 years), gender, color/race, symptoms, pregnancy or puerperium, comorbidities, hospitalization, and death were investigated. Fatality rate and mortality coefficient were calculated, and a multiple logistic regression analysis was performed to determine if gender, age, and comorbidities were factors associated with death. Of 682 pediatric cases, $52.8 \%$ were female, with a mean age of $9 \pm 7.2$ years. The most frequent symptoms were fever (64.4\%), cough (52.4\%), and respiratory distress (32.4\%). Hospitalization was reported in $46.2 \%$ of cases, mainly among neonates (80.3\%) and infants (73.8\%). Thirty-eight deaths were notified, and a fatality rate of 5.6\% (95\% Cl: 3.9-7.3) was found, with higher fatality rates among neonates $11.5 \%$ (7 of 61 ) and $9.5 \%$ (8 of 84 ) infants. The mortality coefficient was 10.9 per 100,000 inhabitants < 1 year of age, whereas comorbidities (Odds ratio [OR] = 14.13, 95\% Cl: 6.35-31.44), age < 30 days $(\mathrm{OR}=5.17,95 \% \mathrm{Cl}: 1.81-14.77)$, and age $1-11$ months $(\mathrm{OR}=3.28,95 \% \mathrm{Cl}: 1.21-8.91)$ were independent factors associated with death. The results demonstrate the vulnerability of neonates and infants with severe conditions, need hospitalization, and high fatality rate, indicating the necessity to adapt public health policies for these age-groups.
\end{abstract}

\section{INTRODUCTION}

The world faces a new disease that originated in late 2019 in China and was declared a pandemic by the WHO on March 11, 2020. ${ }^{1}$ With high transmission capacity, the etiological agent, a coronavirus, was called SARS-CoV-2, whereas the disease corresponded to coronavirus infection disease (COVID-2019). Brazil declared the state of emergency on February 3, 2020 2 and registered the first COVID-19 case in São Paulo on February 25, 2020.

COVID-19 in children and adolescents is intriguing because of its low frequency, severity, and fatality rate. ${ }^{3-6}$ Children aged $<18$ years represented $1.7 \%$ of the total cases in the United States, $1 \%$ in China and the Netherlands, and $2 \%$ in the United Kingdom. ${ }^{7-9}$

The first studies with large pediatric population were conducted in China $^{10}$ and in the United States. ${ }^{7}$ Of 2,135 individuals aged $<18$ years considered exposed in the Chinese study (data up to February 2020), 728 cases (34\%) were confirmed using the reverse-transcriptase-PCR (RT-PCR). Among the confirmed cases (median age of 10 years), $12.9 \%$ were asymptomatic, $43.1 \%$ were classified as mild, $40.9 \%$ moderate, $2.5 \%$ severe, $0.4 \%$ critical, and one died (among the latter classifications, infants were the most vulnerable). ${ }^{10}$ Conversely, in the United States, the CDC reported 2,572 confirmed cases (1.7\% of all cases) and three deaths in children $<18$ years of age (mean age $\sim 11$ years) until April 2020. The frequency of hospitalization was $5.7 \%$, being more frequent in children $<1$ year of age and those with comorbidities. ${ }^{7}$

In Europe, a multicenter study conducted in 25 countries between 1 and 24 April confirmed COVID-19 using the RT-

\footnotetext{
*Address correspondence to Gabrielle R. Sena, IMIP - Instituto de Medicina Integral Prof. Fernando Figueira - Directoria de Ensino - Pos Graduacao stricto sensu, Rua dos Coelhos, 300 Boa Vista, Recife PE 50070-550, Brazil. E-mail: gabriellesena8@gmail.com
}

PCR in 582 patients aged $<19$ years (median age of 5 years). In this population, $62 \%$ were hospitalized $(8 \%$ admitted to the intensive care unit [ICU]), $25 \%$ presented comorbidities, and four died $(0.7 \%) .{ }^{11}$ Two systematic reviews identified comorbidities in $21 \%{ }^{12}$ and $35 \%{ }^{13}$ of the cases, with respiratory diseases (mainly asthma), immunosuppression, and cardiovascular diseases being the most reported.

Despite insufficient inputs for the high demand, the COVID19 confrontation in Latin America and the Caribbean was supported by the Pan American Health Organization, focused on the collaborative surveillance capacity, and based on both the existing system for influenza and the acquisition of molecular testing. ${ }^{14}$ Until May 27, 2020, the most affected countries by the pandemic were Brazil $(391,222$ cases and 74,560 deaths), Peru (129,751/3,788), Chile (82,289/841), and Mexico $(74,560 / 8,134)$ (https://ais.paho.org/phip/viz/ COVID19Table.asp).

In Brazil, a study conducted with 67,180 hospitalized patients until May 31, 2020 reported 1,454 (2.2\%) COVID-19 infections in patients $\leq 20$ years of age. Of these, $116(8.0 \%)$ were neonates, 381 (26.2\%) were 1-12 months, 518 (35.6\%) between 1 and 11 years, and 439 (30.2\%) were adolescents. ${ }^{15}$ Pernambuco, one of the nine states in northeastern Brazil, had its first external and community transmission detected on 12 and March 17, 2020, respectively, with a subsequent rapid increase in the number of cases and deaths. By June 19,2020 , it registered $4.9 \%$ of the $1,032,913$ confirmed cases in Brazil and $8.5 \%$ of the 48,954 deaths. Children aged $\leq 20$ years represented $2.4 \%$ (438 of 17,976 ) of the confirmed cases. ${ }^{16}$

In children, the most frequent symptoms during the acute phase are cough, fever, fatigue, nasal congestion, runny nose, abdominal discomfort or pain, nausea, vomiting, and diarrhea. ${ }^{17}$ Few patients evolve with a respiratory infection and/ or disease worsening, requiring critical care. ${ }^{6,18}$ However, a severe late manifestation of multisystemic inflammatory 
syndrome has been documented, probably associated with SARS-CoV-2. ${ }^{19,20}$

The COVID-19 fatality varies according to the country, age, and disease traceability. The global fatality rate ranges from $2.3 \%$ in China and Korea to $9.2 \%$ in Italy, being lower than $1 \%$ in patients $<50$ years of age as well as in the pediatric

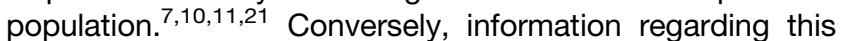
age-group is scarce in developing countries and tropical regions.

In this context, this study aimed to analyze the epidemiological and clinical aspects of patients aged $<20$ years diagnosed with COVID-19 by RT-PCR in one of the first epicenters of the disease in Brazil, the state of Pernambuco. Moreover, a multiple logistic regression was performed to determine if gender, age, and comorbidities were factors associated with death in this population.

\section{METHODS}

The cross-sectional study was conducted in COVID-19 cases (confirmed by RT-PCR) in children and adolescents aged less than 20 years, reported in the state of Pernambuco (Brazil), between February 13, and June 19, 2020. We analyzed secondary data provided by the Secretaria de Planejamento e Gestao de Pernambuco (SEPLAG PE, www.seplag. pe.gov.br), available in the public domain, with no need for approval by the ethics committee in research.

The state of Pernambuco $\left(98,076,021 \mathrm{~km}^{2}\right)$ has an estimated population of 9,616,621 inhabitants, with approximately $32 \%$ people aged 20 years (IBGE, 2020-https:// cidades.ibge.gov.br/brasil/pe/panorama) and 185 municipalities grouped into 12 Regional Health Managements (GERES).

Following the determination of the Brazilian Ministry of Health (https://www.saude.gov.br/noticias/agencia-saude/ 46554-notificacoes-de-casos-serao-feitas-automaticallypelos-estados), the suspected and confirmed cases are notified by the states of the federation to conduct surveillance actions and provide transparency of information. In Pernambuco, the Health Surveillance Secretariat (SES-SEVS) established the notification criteria for COVID-19 through a technical note (4/2020-SES-PE from March 20, 2020), in which the healthcare professionals should immediately notify (up to 24 hours) the Center for Strategic Information in Health Surveillance of Pernambuco (CIEVS-PE) by filling in an electronic form on the surveillance system platform. ${ }^{22}$

Severe COVID-19 cases, with or without hospitalization, were notified in the FormSUS (SRAG's notification form) (https://www.cievspe.com/notifique-aqui), whereas the e-SUS form (individual registration form of the primary healthcare secretariat) was used to report nonhospitalized patients with mild cases (i.e., flu syndrome) (https://notifica.saude.gov.br). Both forms contained epidemiological data, laboratory test results for COVID-19, and the patients' clinical evolution.

Initially, the duplicates between both forms were excluded, and all remaining information was reviewed. For analysis, data regarding age, gender, color/race, symptoms and signs, peripheral oxygen saturation $<95 \%\left(\mathrm{SpO}_{2}<95 \%\right)$, comorbidities, pregnancy or puerperium, place of residence according to the GERES, date of notification, hospitalization, and death were included.

The symptoms registered in the reporting system as "symptoms," "other symptoms," "select the presenting symptoms," "other symptoms (which)," or those included as comorbidities were grouped into the following categories: asymptomatic (without symptoms), fever (fever or chills), adynamia (adynamia, asthenia, prostration, leg tiredness, or weakness), body pain/myalgia (body pain, myalgia, or low back pain), headache (cephalea, headache, or neck pain), runny nose (runny nose, rhinorrhea, or sneezing), nasal obstruction (nasal congestion or obstruction), sore throat (sore throat or throat clearing), cough, respiratory distress (respiratory distress, dyspnea, tachypnea, chest tightness, or nose flaring), $\mathrm{SpO}_{2}<95 \%$, diarrhea, nausea/vomiting, abdominal pain, skin manifestations (skin rash or red spots), smell alterations (smell alteration, smell loss, or anosmia), altered taste (altered taste, taste loss, or ageusia), and other symptoms (malaise, drowsiness, dizziness, anorexia, lack of appetite, tachycardia, and ocular pain and secretion).

The comorbidities reported were grouped into leukemias (acute lymphoblastic leukemia, acute myeloid leukemia, and leukemia), solid tumors (neoplasia, cancer, tumor in the central nervous system or trunk, Wilms' tumor, Ewing's tumor, rhabdomyosarcoma, or hepatoblastoma), chronic pneumopathy (chronic lung disease), asthma, neurological disease (chronic encephalopathy or seizure/epilepsy), hematological disease (sickle cell anemia), autoimmune disease or immunosuppression, prematurity (history of prematurity associated or not with bronchodysplasia), and others (chromosomal abnormalities, heart disease, hydrocephalus, microcephaly, lactose intolerance, hypertension, mental disorder, diabetes mellitus, pneumonia, pleural effusion, or tuberculosis). Patients in the pregnancy-puerperal cycle were also assigned.

Age was grouped into six categories as follows: neonates ( $<30$ days of age), infants (1-11 months of age), 1-4 years, 5-9 years, 10-14 years, and 15-19 years. Mortality rates per 100,000 inhabitants were calculated based on deaths registered in the system and population estimates for the year 2018 , according to data from the information technology department of the public healthcare system (DATASUS) (the latest data referring to the population living in Pernambuco, according to age range, date from 2018) (http://tabnet.datasus.gov.br/cgi/ deftohtm.exe?ibge/cnv/poppe.def).

Data are shown as mean $\pm \mathrm{SD}$, as otherwise stated. Analyzes were performed using the Stata program, version 13.0. Binary univariate and multivariate analyses were carried out through logistic regression to verify the effect of age, gender, and comorbidity on the event (death). For these analyzes, we recategorized the variable age into the following groups: newborns (less than 30 days), infants (1-12 months), children (1-9 years), and adolescents (10-19 years). Independent variables showing a $P$-value $<0.20$ in the univariate analysis were included in the multiple regression model. Backward stepwise procedure was used to obtain adjusted OR (odds ratio $[\mathrm{OR}])$ at the final model. $P$-value $<0.05$ was considered statistically significant.

\section{RESULTS}

A total of 94,140 notifications were found $(65,535$ in the e-SUS from February 13 to June 24, 2020, and 28,605 in the FormSUS between 25 February and June 19, 2020). Seven hundred thirty-one patients met the eligibility criteria (294 from the e-SUS and 437 from the FormSUS) and were grouped in a single database for duplicate exclusion. The age of five 
patients was not found or could not be determined; thus, we considered losses.

In Pernambuco, from March 12 to June 19, 2020, that is, from the 11th to the 25th epidemiological week, 682 cases were confirmed using RT-PCR nasal/oral swab samples.

The mean age of the total sample was $9.1 \pm 7.2$ years, whereas the median and interquartile range (IQR: 25-75\%) was 9.0 (1-16) years. For those 145 children aged < 1 year (mean age of $70.1 \pm 83.4$ days), the lower and upper values were 1 and 327 days, respectively, and the median age was 37.0 (8-97) days (Table 1).

There was a slight predominance of females (52.8\%) in the total sample, with no significant differences between agegroups $(P=0.791)$.

No information regarding race/color was found in $43.7 \%$ of patients. Among those registered, 38.9\% were brown, 13.1\% white, $2.4 \%$ yellow, $1.6 \%$ black, and $0.4 \%$ indigenous.
Signs/symptoms were not notified in $12.3 \%$ of the cases, and the most frequent were fever (64.4\%), cough (52.4\%), and respiratory distress (32.3\%). $\mathrm{SpO}_{2}<95 \%$ was present in $15.1 \%$ records, whereas smell and taste alterations were present in $5.3 \%$ and $4.8 \%$ of the sample, respectively.

Seventy-eight comorbidities were reported in 74 (10.9\%) patients, with the predominance of oncological diseases (5.0\%), and 17 (2.5\%) adolescents were in the pregnancypuerperal cycle (Table 1).

Hospitalization was notified in $46.2 \%$ of cases, and the majority were newborns (80.3\%) and infants (73.8\%); however, information regarding hospitalization was absent in $39.6 \%$ of notifications (Table 1). The cumulative hospitalization rate was 10.1 per 100,000 inhabitants, based on the population aged $<20$ years residing in Pernambuco in 2018 $(3,118,258$, according to DATASUS).

TABLE 1

Distribution of 682 cases of COVID-19 (reverse-transcriptase-PCR SARS-CoV-2 positive) aged < 20 years in Pernambuco, Brazil, from March 12 to June 19, 2020, according to age, gender, symptoms/signs, comorbidities, pregnancy-puerperal cycle, and fatality

\begin{tabular}{|c|c|c|c|c|c|c|c|}
\hline & $<20$ years & $<30$ days & 1-11 months & $1-4$ years & 5-9 years & $10-14$ years & $15-19$ years \\
\hline Age-group & $N(\%)$ & $N(\%)$ & $N(\%)$ & $N(\%)$ & $N(\%)$ & $N(\%)$ & $N(\%)$ \\
\hline Patients & 682 & $61(8.9)$ & $84(12.3)$ & $108(15.8)$ & $89(13.1)$ & $104(15.3)$ & $236(34.6)$ \\
\hline \multicolumn{8}{|l|}{ Gender } \\
\hline Male & $322(47.2)$ & $31(50.8)$ & 45 (53.6) & $52(48.2)$ & $40(44.9)$ & $47(45.2)$ & $107(45.3)$ \\
\hline Female & 360 (52.8) & 30 (49.2) & $39(46.4)$ & $56(51.8)$ & $49(55.1)$ & $57(54.8)$ & $129(54.7)$ \\
\hline \multicolumn{8}{|l|}{ Symptoms/signs* } \\
\hline Asymptomatic & $6(0.9)$ & $1(1.6)$ & $1(1.2)$ & 0 & $2(2.3)$ & $2(1.9)$ & - \\
\hline Fever & $439(64.4)$ & $27(44.3)$ & $51(60.7)$ & 79 (73.2) & $60(67.4)$ & 65 (62.5) & $157(66.5)$ \\
\hline Adynamia & $13(1.9)$ & $1(1.6)$ & $1(1.2)$ & $2(1.9)$ & $2(2.3)$ & $1(1.0)$ & $6(2.5)$ \\
\hline Body pain/myalgia & $33(4.8)$ & $1(1.6)$ & $4(4.8)$ & $3(2.8)$ & $4(4.5)$ & $8(7.7)$ & $13(5.5)$ \\
\hline Headache & $73(10.7)$ & - & $3(3.6)$ & $6(5.7)$ & $8(9.0)$ & $13(12.5)$ & $43(18.2)$ \\
\hline Runny nose & $58(8.5)$ & $3(4.9)$ & $18(21.4)$ & $10(9.3)$ & $6(6.7)$ & $5(4.8)$ & $16(6.8)$ \\
\hline Nasal obstruction & $47(6.9)$ & $2(3.3)$ & $15(17.9)$ & $10(9.3)$ & $3(3.4)$ & $5(4.8)$ & $12(5.1)$ \\
\hline Sore throat & $159(23.3)$ & $5(8.2)$ & $6(7.1)^{\prime}$ & $11(10.2)$ & $23(25.8)$ & $33(31.7)$ & 81 (34.3) \\
\hline Cough & 357 (52.4) & $20(32.8)$ & 44 (52.4) & 61 (56.5) & $38(42.7)$ & $60(57.7)$ & $134(56.8)$ \\
\hline Respiratory discomfort & 220 (32.3) & $33(54.1)$ & $44(52.4)$ & $38(35.2)$ & $24(27.0)$ & $23(22.1)$ & $58(24.6)$ \\
\hline O2 saturation < $95 \%$ & $103(15.1)$ & $13(21.3)$ & $20(23.8)$ & $24(22.2)$ & $12(13.5)$ & $10(9.6)$ & $24(10.2)$ \\
\hline Diarrhea & 76 (11.4) & $5(8.2)$ & $15(17.9)$ & $17(15.7)$ & $15(10.6)$ & $11(10.6)$ & $13(5.5)$ \\
\hline Nausea, vomiting & $50(7.3)$ & - & $8(9.5)$ & $11(10.2)$ & $11(12.4)$ & $8(7.7)$ & $12(5.1)$ \\
\hline Abdominal pain & $7(1.0)$ & - & - & $3(2.8)$ & $3(3.4)$ & $1(1.0)$ & - \\
\hline Skin manifestations & $4(0.6)$ & - & - & $1(0.9)$ & $1(1.2)$ & $1(1.0)$ & $1(0.4)$ \\
\hline Smell alteration & $36(5.3)$ & - & $1(1.2)$ & $3(2.8)$ & $1(1.1)$ & $4(3.9)$ & 27 (11.4) \\
\hline Taste alteration & $33(4.8)$ & - & $1(1.2)$ & $3(2.8)$ & $1(1.1)$ & $3(2.9)$ & 25 (10.6) \\
\hline Other reported symptoms ${ }^{*}$ & $15(2.2)$ & - & - & - & - & - & - \\
\hline No information & $39(5.7)$ & - & - & - & - & - & - \\
\hline \multicolumn{8}{|l|}{ Comorbidities $†$} \\
\hline Leukemia & $19(2.8)$ & - & - & - & - & - & - \\
\hline Solid tumors & $15(2.2)$ & - & - & - & - & - & - \\
\hline Chronic lung disease & $10(1.5)$ & - & - & - & - & - & - \\
\hline Asthma & $5(0.7)$ & - & - & - & - & - & - \\
\hline Neurological disease & $9(1.3)$ & - & - & - & - & - & - \\
\hline $\begin{array}{l}\text { Autoimmune disease/ } \\
\text { immunosuppression }\end{array}$ & $3(0.4)$ & - & - & - & - & - & - \\
\hline Hematological disease & $3(0.4)$ & - & - & - & - & - & - \\
\hline $\begin{array}{l}\text { History of prematurity } \pm \\
\text { bronchodysplasia }\end{array}$ & $4(0.6)$ & - & - & - & - & - & - \\
\hline Other & $10(1.5)$ & - & - & - & - & - & - \\
\hline Pregnancy/puerperium & $17(2.5)$ & - & - & - & - & $1(1.0)$ & $16(6.8)$ \\
\hline \multicolumn{8}{|l|}{ Hospitalization } \\
\hline Yes & $315(46.2)$ & $49(80.3)$ & $62(73.8)$ & $67(62.0)$ & $33(37.1)$ & $38(36.5)$ & $66(28.0)$ \\
\hline No & 97 (14.2) & $5(8.2)$ & $8(9.5)$ & 15 (13.9) & $13(14.6)$ & $17(16.4)$ & 39 (16.5) \\
\hline No information & 270 (39.6) & $7(11.5)$ & $14(16.7)$ & $26(24.7)$ & $43(48.3)$ & $49(47.1)$ & $131(55.5)$ \\
\hline Death (fatality rate) & $38(5.6)$ & $7(11.5)$ & $8(9.5)$ & $6(5.6)$ & $5(5.6)$ & 2 (1.92) & $10(4.24)$ \\
\hline
\end{tabular}

Data were provided by the Secretariat of Planning and Management of Pernambuco (SEPLAG PE).

Other symptoms = malaise, drowsiness, dizziness, anorexia, tachycardia, otalgia, ocular pain, ocular secretion.

† Seventy patients presented with one comorbidity and four with two comorbidities; Other comorbidities: two children with chromosomal abnormalities, one with congenital heart disease and hydrocephalus, two with microcephaly, one with lactose intolerance, one with hypertension, one with mental disorder, one with diabetes mellitus, one with pneumonia and pleural effusion, and one with tuberculosis. 


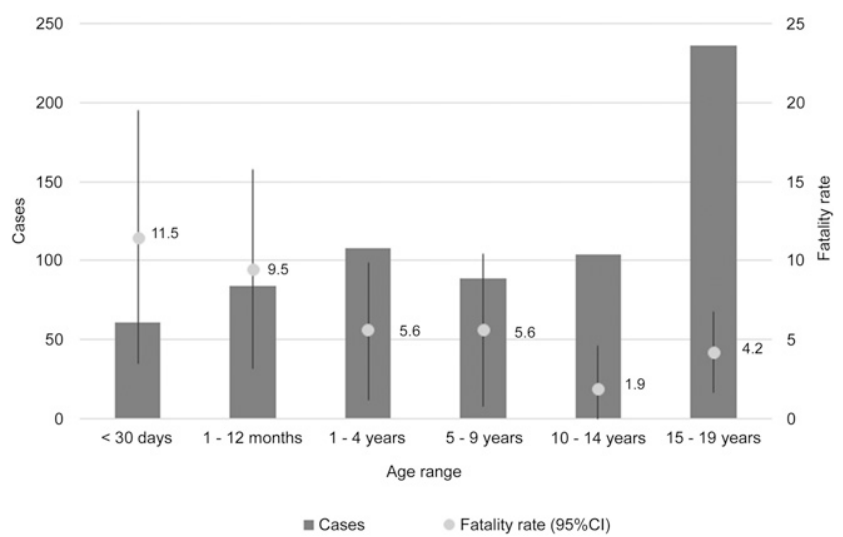

FIGURE 1. Number of cases and fatality rate of COVID-19 cases according to age-group. $95 \% \mathrm{Cl}$. Pernambuco, March 12 to June 19 , 2020. Secondary data obtained from the Secretariat of Planning and Management of Pernambuco (SEPLAG PE).

Thirty-eight of 682 patients died (overall mortality rate of 5.6\% [95\% Cl: 3.9-7.3]). As shown in Figure 1, the fatality rate by age-group was higher in the neonatal period $(11.5 \%, 95 \%$ $\mathrm{Cl}: 3.5-19.5)$ and in infants $(9.5 \%, 95 \% \mathrm{Cl}: 3.2-15.8)$ than that in those aged $1-4$ years $(5.6 \%, 95 \% \mathrm{Cl}: 1.2-9.9), 5-9$ years (5.6\%, 95\% Cl: $0.8-10.4), 10-14$ years $(1.9 \%, 95 \% \mathrm{Cl}:$ $1.3-4.6)$, and $15-19$ years $(4.2 \%, 95 \% \mathrm{Cl}: 1.7-6.8)$. No deaths were reported among pregnant or postpartum adolescents. Table 2 shows that the higher mortality rate per 100,000 inhabitants, according to age-group, was observed in children aged $<1$ year $(10.9)$.

The adjusted analyses showed comorbidities $(\mathrm{OR}=14.13$, 95\% Cl: 6.35-31-44) and lower age-group (neonates [OR = 5.17, 95\% Cl:1.81-14.77] and infants [OR $=3.28,95 \% \mathrm{Cl}$ : 1.21-8.91]) as independent factors associated with death (Table 3).

\section{DISCUSSION}

This study describes the clinical epidemiological findings of 682 COVID-19 cases confirmed by RT-PCR in children aged less than 20 years during the first three pandemic months (from March 12 to June 19, 2020) in Pernambuco, one of the epicenters of the disease in Brazil. The main limitation of this retrospective study (which was based on the notifications carried out during the assistance to patients during the epidemic) is the absence or inadequacy of data entry for some variables, such as race/color, that did not allow a more detailed analysis of the risk factors reported in the literature. In

TABLE 2

Mortality rates (per 100,000 inhabitants) by COVID-19, according to age-group, in Pernambuco, from March 12 to June 19, 2020

\begin{tabular}{|c|c|c|c|}
\hline & Deaths & Population $^{*}$ & \multirow[b]{2}{*}{ Deaths per $100.00 \mathrm{C}$} \\
\hline & N & N & \\
\hline$<12$ months (including < 30 days) & 15 & 137,885 & 10.87 \\
\hline $1-4$ years & 6 & 549,741 & 1.09 \\
\hline $5-9$ years & 5 & 755,970 & 0.66 \\
\hline $10-14$ years & 2 & 848,443 & 0.24 \\
\hline $15-19$ years & 10 & 826,219 & 1.21 \\
\hline Total $<20$ years & 38 & $3.118,258$ & 1.21 \\
\hline
\end{tabular}

this analysis, it was considered that only the most serious comorbidities were reported. On the other hand, it is noteworthy the fact that data collection occurred during the epidemic peak, that all cases were confirmed by RT-PCR SARS-Cov-2, and that death was the outcome analyzed. There was a restriction of this molecular test at the time of the study, and only the severe cases were tested to confirm the diagnosis. Therefore, the case fatality rates may have been overestimated, but this overestimation should have occurred in all age-groups.

Fatality and mortality were high in neonates and infants, and the most predominant symptoms and signs were fever, cough, and respiratory distress. Also, comorbidities and lower age (neonates and infants) were independent factors associated with death.

The median/mean age observed was higher than those reported in the English and Chinese studies (3.9 and 7 years, respectively) and lower than those in the Italian and American reports (11 years). ${ }^{7,10,23,24}$ The median age may vary according to the age distribution of the studied population, data origin (community- or hospital-based), and diagnostic test availability.

The most prevalent signs and symptoms were similar to other countries $7,10,12,13,24$; however, it was not possible to perform a more accurate clinical severity classification. ${ }^{22}$ It is worth noting that approximately one-third of the patients presented respiratory distress, whereas half had hypoxemia, indicating that the registered cases were more severe, especially among neonates and infants. ${ }^{24}$

Severe illness and death were rarely described in pediatric patients at the beginning of the COVID-19 pandemic, probable because of the greater resistance to infections (i.e., agedependent susceptibility), higher frequency of asymptomatic or paucisymptomatic cases compared with adults (i.e., agedependent severity), and/or adoption of social confinement measures with the closure of schools and child-care centers. ${ }^{25}$

A multicentric study conducted in Italy (from February 27 to May 8, 2020) described that among hospitalized children $<18$ years of age, the highest rate (36.6\%) occurred among children $<1$ year old. ${ }^{24}$ With the progression of the pandemic, data from the CDC demonstrated that, although the cumulative hospitalization rate was lower than that observed in adults (8.0 versus 164.5 per 100,000 inhabitants), one of three hospitalized children needed critical care. ${ }^{26}$ In our study, the cumulative hospitalization rate during the studied period was 10.1 per 100,000 inhabitants aged less than 20 years, and the frequency of hospitalizations was high among newborns and infants $(80.3 \%$ and $73.8 \%$, respectively); however, it was not possible to establish the critical care admissions. These results may reflect both the characteristics of the studied population (with few asymptomatic and mild cases) and the social vulnerability situation observed in Pernambuco.

Compared with adults, the greater COVID-19 severity and fatality were observed in children $<1$ year of age and adolescents. ${ }^{7,23,26}$ Cases involving children and adolescents with severe forms of the disease have been described more frequently and are related to the late manifestation of the disease. ${ }^{19,20,27}$ However, fatal cases remain uncommon in high-income countries $(<1 \%)^{7,10,11}$ and were associated with comorbidities, such as diabetes and obesity. ${ }^{7,10,11,23,26,27}$ In our study, fatality and mortality from a specific cause were higher in the neonates and children $<1$ year of age, and obesity was not described as a comorbidity in this population. 
TABLE 3

Non-adjusted and adjusted analyses of factors associated with death by COVID-19 in patients aged < 20 years between March 12 and June 19 , 2020 in Pernambuco, Brazil

\begin{tabular}{|c|c|c|c|c|c|c|c|c|}
\hline \multirow[b]{3}{*}{ Variable } & \multicolumn{2}{|c|}{ Deaths } & & & & & & \\
\hline & \multirow{2}{*}{$\begin{array}{c}\text { Yes } \\
N(\%)\end{array}$} & \multirow{2}{*}{$\frac{\text { No }}{N(\%)}$} & \multicolumn{3}{|c|}{ Univariate analysis $^{*}$} & \multicolumn{3}{|c|}{ Multivariate analysis* } \\
\hline & & & OR & $(95 \% \mathrm{Cl})$ & $P$-value & OR & $(95 \% \mathrm{Cl})$ & $P$-value \\
\hline \multicolumn{9}{|l|}{ Gender } \\
\hline Male & $19(5.9)$ & 303 (94.1) & 1.13 & $(0.88-2.17)$ & 0.72 & - & - & - \\
\hline Female & 19 (5.3) & 341 (94.7) & 1 & - & - & - & - & - \\
\hline \multicolumn{9}{|l|}{ Age range } \\
\hline$<30$ days & $7(11.5)$ & 54 (88.5) & 3.54 & $(1.34-9.40)$ & 0.011 & 5.17 & $(1.81-14.77)$ & 0.002 \\
\hline $1-11$ months & $8(9.5)$ & $76(90.5)$ & 2.88 & (1.14-7.28) & 0.026 & 3.28 & $(1.21-8.91)$ & 0.020 \\
\hline $1-9$ years & $11(5.6)$ & $186(94.4)$ & 1.62 & $(0.70-3.74)$ & 0.261 & 0.83 & (0.33-2.08) & 0.697 \\
\hline 10-19 years & $12(3.5)$ & $328(96.5)$ & 1 & - & - & - & - & - \\
\hline \multicolumn{9}{|l|}{ Comorbidities* } \\
\hline No & $20(3.3)$ & 588 (96.7) & 1 & - & - & - & - & - \\
\hline Yes & $18(24.3)$ & $56(75.7)$ & 9.45 & (4.72-18.90) & $<0.001$ & 14.13 & (6.35-31.44) & $<0.001$ \\
\hline
\end{tabular}

${ }^{\star}$ Note: logistic regression.

In Pernambuco, comorbidities, age < 30 days, and age between 1 and 11 months were identified as independent factors associated with death. Gender was not an associated factor, and race/color was not included to data absence in almost half of the records. Although no other studies have performed multiple analyses with death as the main outcome, two studies have evaluated the factors associated with greater disease severity and ICU admission. ${ }^{23,24}$ Similar to our results, an Italian community-based study showed that age $<1$ year and comorbidities represented risk factors for disease severity. ${ }^{24}$ In England, a hospital-based study showed that age less than 30 days, age between 10 and 14 years, and black ethnicity were factors associated with ICU admission. ${ }^{23}$

The history of pediatric COVID-19 has been built throughout the pandemic with late reports of severe multisystemic inflammatory syndrome manifestations associated with SARSCoV- $2^{19,20,28}$ and possible sequelae. For this reason, the true COVID-19 load in children $<20$ years of age cannot be estimated yet. 4,5

Similar to adults, our results highlight the high fatality rate and vulnerability of neonates and infants aged $<12$ months with severe conditions requiring hospitalization. In this sense, public policies must face the peculiarities involving this agegroup, whereas maintaining social distance and the reopening of child-care centers should be widely discussed. Also, the management of neonatal and pediatric ICUs, the appropriate training of health professionals focused on early recognition, surveillance, and immediate treatment of potentially severe cases should be discussed. In the moment that the scientific community does not seem to suggest the inclusion of children aged less than 1 year in the priority groups for a possible vaccine, our findings reinforce the need to better discuss the epidemiological importance of this age-group.

Received October 26, 2020. Accepted for publication February 1, 2021.

Published online February 18, 2021

Acknowledgments: We would like to thank all health professionals involved with the care of children with COVID-19 and the SEPLAG-PE for data availability. The American Society of Tropical Medicine and Hygiene has waived the Open Access fee for this article due to the ongoing COVID-19 pandemic and has assisted with publication expenses.
Authors' addresses: Gabrielle R. Sena, Instituto de Medicina Integral Prof. Fernando Figueira, Recife, Brazil, Faculdade Pernambucana de Saúde, Recife, Brazil, and Universidade de Pernambuco, Recife, Brazil, E-mail: gabriellesena8@gmail.com. Tiago P. F. Lima, Instituto de Medicina Integral Prof. Fernando Figueira, Recife, Brazil, and Instituto Federal de Pernambuco, Garanhuns, Brazil, E-mail: tiagopessoalim@gmail.com. Suely A. Vidal, Maria do Carmo M. B. Duarte, Mecneide M. Lins, Leuridan C. Torres, and Maria Julia G. Mello, Instituto de Medicina Integral Prof. Fernando Figueira, Recife, Brazil, E-mails: suelyarruda@hotmail.com, mcduarte2010@gmail.com, mecneide.mendes@gmail.com, leuridan.torres@imip.org.br, and mjuliagmello@gmail.com. Patrícia G. M. Bezerra and Eduardo J. Fonseca Lima, Instituto de Medicina Integral Prof. Fernando Figueira, Recife, Brazil, and Faculdade Pernambucana de Saúde, Recife, Brazil, E-mails: pmvbezerra@gmail.com and eduardojorge@imip.org.br. Cynthia Braga, Lívia B. de Andrade, and Jurema T. O. Lima, Instituto de Medicina Integral Prof. Fernando Figueira, Recife, Brazil, and Instituto Ageu Magalhães - Fiocruz PE, Recife, Brazil, E-mails: cynthiabraga27@ gmail.com, ftliviabandrade@gmail.com, and jurematsales@gmail.com.

This is an open-access article distributed under the terms of the Creative Commons Attribution (CC-BY) License, which permits unrestricted use, distribution, and reproduction in any medium, provided the original author and source are credited.

\section{REFERENCES}

1. World Health Organization, 2020. Coronavirus Disease (COVID-19) Outbreak. Available at: https://www.who.int/Westernpacific/ emergencies/covid-19. Accessed June 11, 2020.

2. Croda J, Oliveira WK, Frutuoso RL, Mandetta LH, Baia-da-Silva DC, Brito-Sousa JD, Monteiro WM, Lacerda MVG, 2020. COVID-19 in Brazil: advantages of a socialized unified health system and preparation to contain cases. Rev Soc Bras Med Trop 53: e20200167.

3. Jesus JG et al., 2020. Importation and early local transmission of COVID-19 in Brazil, 2020. Rev Inst Med Trop Sao Paulo 62: e30.

4. Safadi MAP, 2020. The intriguing features of COVID-19 in children and its impact on the pandemic. J Pediatr (Rio J) 96: 265-268.

5. Li R, Pei S, Chen B, Song Y, Zhang T, Yang W, Shaman J, 2020. Substantial undocumented infection facilitates the rapid dissemination of novel coronavirus (SARS-CoV-2). Science 368: 489-493.

6. Castagnoli R, Votto M, Licari A, Brambilla I, Bruno R, Perlini S, Rovida F, Baldanti F, Marseglia GL, 2020. Severe acute respiratory syndrome coronavirus 2 (SARS-CoV-2) infection in children and adolescents: a systematic review. JAMA Pediatr 174: 882-889.

7. CDC, 2020. Coronavirus disease 2019 in children - United States, February 12-April 2, 2020. MMWR Morb Mortal Wkly Rep 69: 422-426. 
8. Guan WJ et al., 2020. Clinical characteristics of coronavirus disease 2019 in China. New Engl J Med 382: 1708-1720.

9. Docherty $A B$ et al., 2020. Features of 20133 UK patients in hospital with COVID-19 using the ISARIC WHO clinical characterisation protocol: prospective observational cohort study. BMJ 369: $\mathrm{m} 1985$.

10. Dong Y, Mo X, Hu Y, Qi X, Jiang F, Jiang Z, Tong S, 2020. Epidemiology of COVID-19 among children in China. Pediatrics 145.

11. Gotzinger F et al., 2020. COVID-19 in children and adolescents in Europe: a multinational, multicentre cohort study. Lancet Child Adolesc Health 4: 653-661.

12. Patel NA, 2020. Pediatric COVID-19: systematic review of the literature. Am J Otolaryngol 41: 102573.

13. Hoang A, Chorath K, Moreira A, Evans M, Burmeister-Morton F, Burmeister F, Naqvi R, Petershack M, Moreira A, 2020. COVID19 in 7780 pediatric patients: a systematic review. EClinicalMedicine 24: 100433.

14. Andrus JK, Evans-Gilbert T, Santos JI, Guzman MG, Rosenthal PJ, Toscano C, Valenzuela MT, Siqueira M, Etienne C, Breman JG, 2020. Perspectives on battling COVID-19 in countries of Latin America and the Caribbean. Am J Trop Med Hyg 103: 593-596.

15. de Souza WM et al., 2020. Epidemiological and clinical characteristics of the COVID-19 epidemic in Brazil. Nat Hum Behav 4: 856-865.

16. Informe epidemiológico $n^{\circ} 111$. Available at: https://cievspe.com/ novo-coronavirus-2019-ncov. Accessed May 5, 2020.

17. Lu X et al., 2020. SARS-CoV-2 infection in children. N Engl J Med 382: 1663-1665.

18. Shen K et al., 2020. Diagnosis, treatment, and prevention of 2019 novel coronavirus infection in children: experts' consensus statement. World J Pediatr 16: 223-231.
19. Riphagen S, Gomez X, Gonzalez-Martinez C, Wilkinson N, Theocharis P, 2020. Hyperinflammatory shock in children during COVID-19 pandemic. Lancet 395: 1607-1608.

20. Verdoni L, Mazza A, Gervasoni A, Martelli L, Ruggeri M, Ciuffreda M, Bonanomi E, D'Antiga L, 2020. An outbreak of severe Kawasaki-like disease at the Italian epicentre of the SARSCoV-2 epidemic: an observational cohort study. Lancet 395: 1771-1778.

21. Kang SJ, Jung SI, 2020. Age-related morbidity and mortality among patients with COVID-19. Infect Chemother 52: 154-164.

22. Nota Técnica SES/PE No1/2020. Available at: https://cievspe. com/novo-coronavirus-2019-ncov. Accessed June 6, 2020.

23. Swann OV et al., 2020. Clinical characteristics of children and young people admitted to hospital with COVID-19 in United Kingdom: prospective multicentre observational cohort study. BMJ 370: m3249.

24. Bellino $S$ et al., 2020. COVID-19 disease severity risk factors for pediatric patients in Italy. Pediatrics 146: e2020009399.

25. Davies NG, Klepac P, Liu Y, Prem K, Jit M, CMMID COVID-19 Working Group, Eggo RM, 2020. Age-dependent effects in the transmission and control of COVID-19 epidemics. Nat Med 26: 1205-1211.

26. Zachariah $P$ et al., 2020. Epidemiology, clinical features, and disease severity in patients with coronavirus disease 2019 (COVID-19) in a children's hospital in New York city, New York. JAMA Pediatr 174: e202430.

27. Shekerdemian LS et al., 2020. Characteristics and outcomes of children with coronavirus disease 2019 (COVID-19) infection admitted to US and Canadian pediatric intensive care units. JAMA Pediatr 174: 868-873.

28. Ahmed $\mathrm{M}$ et al., 2020. Multisystem inflammatory syndrome in children: a systematic review. EClinicalMedicine 26: 100527. 